\title{
Occurrence of red clay horizon in soil profiles of the Yellow River Delta: Implications for accumulation of heavy...
}

Article in Journal of Geochemical Exploration · November 2015

DOI: 10.1016/j.gexplo.2015.11.006

CITATION

1

5 authors, including:

\section{Haibo Zhang}

Chinese Academy of Sciences

56 PUBLICATIONS 1,241 CITATIONS

SEE PROFILE
READS

56

Chen Tu

Chinese Academy of Sciences 26 PUBLICATIONS 305 CITATIONS

SEE PROFILE 


\title{
Occurrence of red clay horizon in soil profiles of the Yellow River Delta: Implications for accumulation of heavy metals
}

\author{
Yuan $\mathrm{Li}^{\mathrm{a}, \mathrm{b}}$, Haibo Zhang ${ }^{\mathrm{a}, \mathrm{b}}$, Chen Tu${ }^{\mathrm{a}}$, Fang Song ${ }^{\mathrm{a}, \mathrm{b}}$, Yongming Luo ${ }^{\mathrm{a}, \mathrm{b}, *}$ \\ ${ }^{a}$ Key Laboratory of Coastal Environmental Processes and Ecological Remediation, Yantai Institute of Coastal Zone Research, Chinese Academy of Sciences, Yantai 264003, PR China \\ b University of Chinese Academy of Sciences, Beijing 100049, PR China
}

\section{A R T I C L E I N F O}

\section{Article history:}

Received 15 May 2015

Revised 28 September 2015

Accepted 9 November 2015

Available online $\mathrm{xxxx}$

\section{Keywords:}

Yellow River Delta

Soil profile

Red clay horizon

Heavy metals

Geochemical accumulation

\begin{abstract}
A B S T R A C T
The source-area weathering and pedogenesis processes in the alluvial soil profiles might affect depth distribution of heavy metals. Red clay horizon (RCH) with a thickness of $5-50 \mathrm{~cm}$ in a $1 \mathrm{~m}$ soil profile has been found ubiquitously in the Yellow River Delta (YRD). The occurrence of this RCH was supposed to be related with the frequent shifting of the Yellow River tail channel in the Yellow River Delta (YRD). The geochemical features of the RCH were distinct from its upper or lower yellow silt horizon (YSH). The average median grain size of the RCH $(10.5 \mu \mathrm{m})$ was almost three times lower than that of the YSH $(29.9 \mu \mathrm{m})$. Meanwhile, the RCH was characterized of higher chemical index of alteration (CIA), magnetic susceptibility $\left(\chi_{\mathrm{If}}\right)$ and frequency-dependent magnetic susceptibility $\left(\chi_{\mathrm{fd}}\right)$ values than the YSH, which implied a stronger source-area weathering and pedogenesis intensity of the $\mathrm{RCH}$. Besides the distinctive characteristics of the $\mathrm{RCH}$, it also accumulated significantly $(p<0.05)$ higher mean contents of $\mathrm{Cu}, \mathrm{Zn}, \mathrm{Pb}, \mathrm{Cr}, \mathrm{Ni}$ and $\mathrm{Co}$, and maximum content of $\mathrm{Cd}$ in the $\mathrm{RCH}$ than that in the YSH. The principal component analysis (PCA) suggested that distribution of the heavy metals in the YRD soil profiles was significantly related to the content of aluminosilicates, oxides, clay fraction, $\chi_{\mathrm{If}}$ and $\chi_{\mathrm{fd}}$, however, such a correlation was not found except for $\mathrm{Pb}$ in the YSH. In addition, result of $\mathrm{BCR}$ sequential extraction indicated that a higher percentage of Fe-Mn oxides associated fraction was in the $\mathrm{RCH}$ than in the YSH for the heavy metals of $\mathrm{Pb}$ and $\mathrm{Co}$. Cadmium was observed at higher percentage of exchangeable fraction in the $\mathrm{RCH}$ than in the YSH, implying a higher environmental risk of the $\mathrm{Cd}$ in the $\mathrm{RCH}$.
\end{abstract}

c 2015 Published by Elsevier B.V.

\section{Introduction}

Heavy metal pollution in soils has received extensive attention due to its covert, persistent and irreversible properties (Cheng et al., 2014). In general, the fate and speciation of heavy metals in soils are controlled by a variety of physico-chemical properties, including $\mathrm{pH}$, organic matter, clay minerals, cation exchange capacity (CEC), carbonates, phosphates and Fe-Mn oxides (Bai et al., 2011; Selim, 2013). Therefore, different types of soil horizons might affect the content of heavy metals greatly because of their variation in physico-chemical characteristics formed in different environment conditions. Sterckeman et al. (2000) demonstrated that higher concentrations of heavy metals were accumulated in the deeper mineral soil horizons than the humus rich soil horizons. Lamy et al. (2006) presented that the concentrations of the metals were markedly diminished blow a plow pan in soil profile. Burkhardt et al. (2011) reported that high heavy metal concentrations

\footnotetext{
* Corresponding author at: Key Laboratory of Coastal Environmental Processes and Ecological Remediation, Yantai Institute of Coastal Zone Research, Chinese Academy of Sciences, Yantai 264003, PR China.

E-mail address: ymluo@yic.ac.cn (Y. Luo).
}

occurred both in solid phase and in the pore water of an oxidized, iron-rich Btlc horizon of a Luvic Gleysol. Vacca et al. (2012) presented that the soils with the presence of buried horizons in the flooded areas were significantly contaminated by heavy metals.

The accumulation level of heavy metals in soils is usually assessed by the measurement of total heavy metal content. However, it cannot provide sufficient information to evaluate the mobility of actually and potentially mobile metals in soil profiles, and consequently the environmental risk (Kabala and Singh, 2001). As a consequence, sequential extraction procedure by using different mild chemical reagents was developed to evaluate the heavy metal fractions (Tessier et al., 1979; Luo and Christie, 1998a). Hence the heavy metal fractions can be used to assess the mobility in soils (Luo and Christie, 1998b; Nemati et al., 2011).

Previous studies on the heavy metal pollution in soils of the YRD mainly focused on the wetland, which showed unpolluted or moderately polluted levels of heavy metals (Bai et al., 2012; Xie et al., 2014; Yao et al., 2015). These studies also showed that soil organic matter, moisture and clays were key factors to influence the distribution of heavy metals in this area. Liu et al. (2015) applied sequential extraction method to show that most heavy metals in sediments at the Yellow River estuary were presented in the residual fraction. 
However, little information is available on geochemical variability of heavy metals in soil profiles with different weathering features at the whole-delta scale.

In this study, 33 soil profiles were collected from the YRD in November 2012. Among them, 28 soil profiles were found with a special soil horizon named red clay horizon ( $\mathrm{RCH})$. Therefore, the objectives of this study were (1) to understand the geochemical characteristics of the different alluvial horizons in soil profiles, especially focusing on the red clay horizon; (2) to infer the factors influencing the accumulation of heavy metals in the different soil horizons; and (3) to assess the mobility of heavy metals in the typical soil profiles by using the sequential extraction procedure.

\section{Materials and methods}

\subsection{Study area}

Study area is located at the Yellow River Delta, one of China's three major river deltas, has been undergoing extensive development of industry and agriculture according to plans of Chinese central government. The Yellow River, which historically carries a huge amount of sediment $\left(1.08 \times 10^{9} \mathrm{tyr}^{-1}\right)$ from the erosion of Loess Plateau in central China (Milliman and Syvitski, 1992), has been discharging into the western Bohai Sea since 1855 and forming the modern Yellow River Delta (YRD) with expanding by about $20 \mathrm{~km}^{2}$ per year (Pang and Si, 1980). Due to high sediment concentration, the unstable Yellow River distributary channels on the delta has shift their courses for a total of 11 times, resulting in the formation of different sedimentary successions with fine grained layers at weak hydrodynamics and coarse grained layers at strong hydrodynamics (Xue et al., 2009; Qiao et al., 2011a). The main geomorphologic classes built by Yellow River channel movements and sediment deposition in the YRD are distributary channel, crevasse splay, natural levee and flood plain. The textures of deltaic sediment are generally classified as brown clayey silt for flood plain and yellow silt for other landforms (Yi et al., 2003). The region of the red clay horizon with $5-50 \mathrm{~cm}$ thick occurred in $1 \mathrm{~m}$ soil profiles in the study area stretches from the Majia River in the north to the Xiaoqing River in the south, including Dongying City and Binzhou City (Fig. 1a).

\subsection{Soil sampling}

Thirty three soil profiles were collected from inland to coast at the YRD in November 2012. Soils were sampled by pedogenic horizons from bottom to top in $1 \mathrm{~m}$ depth. Samples from thin or discontinuous horizons were added to the horizon above or below. A total of $42 \mathrm{RCH}$ samples were identified in 28 soil profiles (Fig. 1a, marked in red). According to the lithologic characteristics, the soil profile could be divided into three parts (Fig. 1b), the $\mathrm{RCH}$, which have reddish brown color and abundant clay. The upper and lower parts of the RCH with 52 and 26 horizon samples, which have yellow color and abundant silt, were classified as yellow silt horizon (YSH). All soil samples were collected using a stainless steel hand auger and then placed into polyethylene bags.

\subsection{Sample analysis}

All soil samples were air dried at room temperature for one week and sieved through a 2-mm nylon sieve to remove coarse debris, plant roots and other waste materials. They were then ground with a pestle and mortar until all particles passed a $0.149-\mathrm{mm}$ nylon sieve. The 2-mm samples were used for the determination of soil grain size, salinity and $\mathrm{pH}$. The $0.145-\mathrm{mm}$ samples were used for the measurement of soil organic matter (SOM), total nitrogen (TN), cation exchange capacity (CEC), $\mathrm{CaCO}_{3}$, magnetic properties, major elements and heavy metals.

Soil grain size was measured using a Malvern Mastersizer 2000 instrument after removing organic matter and carbonates using $15 \% \mathrm{H}_{2} \mathrm{O}_{2}$ and $4 \mathrm{M} \mathrm{HCl}$. Soil salinity and $\mathrm{pH}$ was determined in supernatant of 1:5 and 1:2.5 soil-water mixtures, respectively. SOM was measured using dichromate oxidation. TN was analyzed on a Vario MACRO cube elemental analyzer. Soil CEC was determined using sodium acetate-ammonium acetate extraction. The $\mathrm{CaCO}_{3}$ equivalent was determined by neutralization with $\mathrm{HCl}$ and back titration with $\mathrm{NaOH}$. Soil magnetic susceptibility was measured at low $(0.47 \mathrm{kHz})$ $\left(\chi_{\mathrm{lf}}\right)$ and high $(4.7 \mathrm{kHz})$ frequency $\left(\chi_{\mathrm{hf}}\right)$ using a Bartington MS2 meter. Frequency dependent susceptibility $\left(\chi_{\mathrm{fd}} \%\right)$ was calculated as $\left(\chi_{\mathrm{lf}}-\right.$ $\left.\chi_{\mathrm{hf}}\right) / \chi_{\mathrm{lf}} \times 100 \%$.

Major and trace elements, including $\mathrm{K}, \mathrm{Ca}, \mathrm{Na}, \mathrm{Al}, \mathrm{Si}, \mathrm{Cu}, \mathrm{Zn}, \mathrm{Cr}, \mathrm{Ni}, \mathrm{Pb}$ and $\mathrm{Co}$ in the soil, were determined by X-ray fluorescence spectroscopy (XRF, Philips Magix Pro PW2440 instrument). Briefly, $4.0 \mathrm{~g}$ of each soil sample was weighed and backing with $2.0 \mathrm{~g}$ boric acid in the mold, then pressed it into a 32-mm diameter pellet at $30 \mathrm{t}$ pressure for $10 \mathrm{~s}$. The prepared powder pellets were directly measured on XRF. Cd was determined by ICP-MS (ELAN DRC II, Perkin Elmer) after highpressure Teflon bomb digestion with strong acids such as $\mathrm{HF}(5 \mathrm{~mL})$, $\mathrm{HNO}_{3}(2 \mathrm{~mL})$ and $\mathrm{HClO}_{4}(1 \mathrm{~mL})$ at $180{ }^{\circ} \mathrm{C}$ for $12 \mathrm{~h}$ (Pretorius et al., 2006). Quality assurance and quality control were assessed using duplicates and standard reference materials (GSS-1, GSS-4, GSS-6, GSS-8) from National Research Center for Certified Reference Materials of China with $10 \%$ of the samples. The recoveries for the major elements and heavy metals in the standards were ranged from 95 to $105 \%$.

The optimized BCR sequential extraction procedure was performed to determine chemical fractionations of heavy metals in the soil samples. This method was described in detail by Nemati et al. (2011). The chemical fractions obtained in each step by the BCR method are shown in Table 1. It was applied to $1 \mathrm{~g}$ soil samples in duplicate into a centrifuge tube. The tube was shaken for $16 \mathrm{~h}$ at room temperature. The extract was separated from the solid phase by centrifugation at $3000 \mathrm{rpm}$ for $20 \mathrm{~min}$. The metal concentrations of the extracts were analyzed by ICP-MS (ELAN DRC II, Perkin Elmer).

\subsection{Geoaccumulation index and pollution index}

The geoaccumulation index ( $\left.I_{\text {geo }}\right)$ and pollution index $\left(I_{\mathrm{POLL}}\right)$ were utilized to assess the intensity of heavy metal pollution in soil profiles. The $I_{\text {geo }}$ was calculated using the equation developed by Müller (1979):

$I_{\text {geo }}=\log _{2}\left[C_{n} /\left(1.5 \times B_{n}\right)\right]$

where $C_{n}$ is the measured concentration of the element $\mathrm{n}$ in a sample and $B_{n}$ is the natural background concentration of this element. These geochemical background values were obtained based on the mean values of environmental background concentrations of the $A$ and $\mathrm{C}$ horizons of Shandong Province (China National Environmental Monitoring Center (CNEMC), 1990).

The $I_{\text {POLL }}$ was computed using the equation developed by Karbassi et al. (2008):

$I_{\mathrm{POLL}}=\log _{2}\left(B_{\mathrm{c}} / L_{\mathrm{p}}\right)$

where $I_{\text {POLL }}, B_{\mathrm{c}}$ and $L_{\mathrm{p}}$ are indicative of pollution intensity, bulk concentration and lithogenous portion, respectively. The residual fraction of heavy metals in BCR sequential extraction was categorized as the lithogenous portion of metals.

\subsection{Statistical analysis}

All multivariate statistical analyses, including ANOVA analysis and principal component analysis (PCA), were conducted using SPSS 20.0 for windows. ANOVA analysis was employed to test the differences among three soil genetic horizons. Differences are considered to be significant if $p<0.05$. Varimax with Kaiser normalization was applied as the rotation method in the PCA. 
$\mathbf{a}$

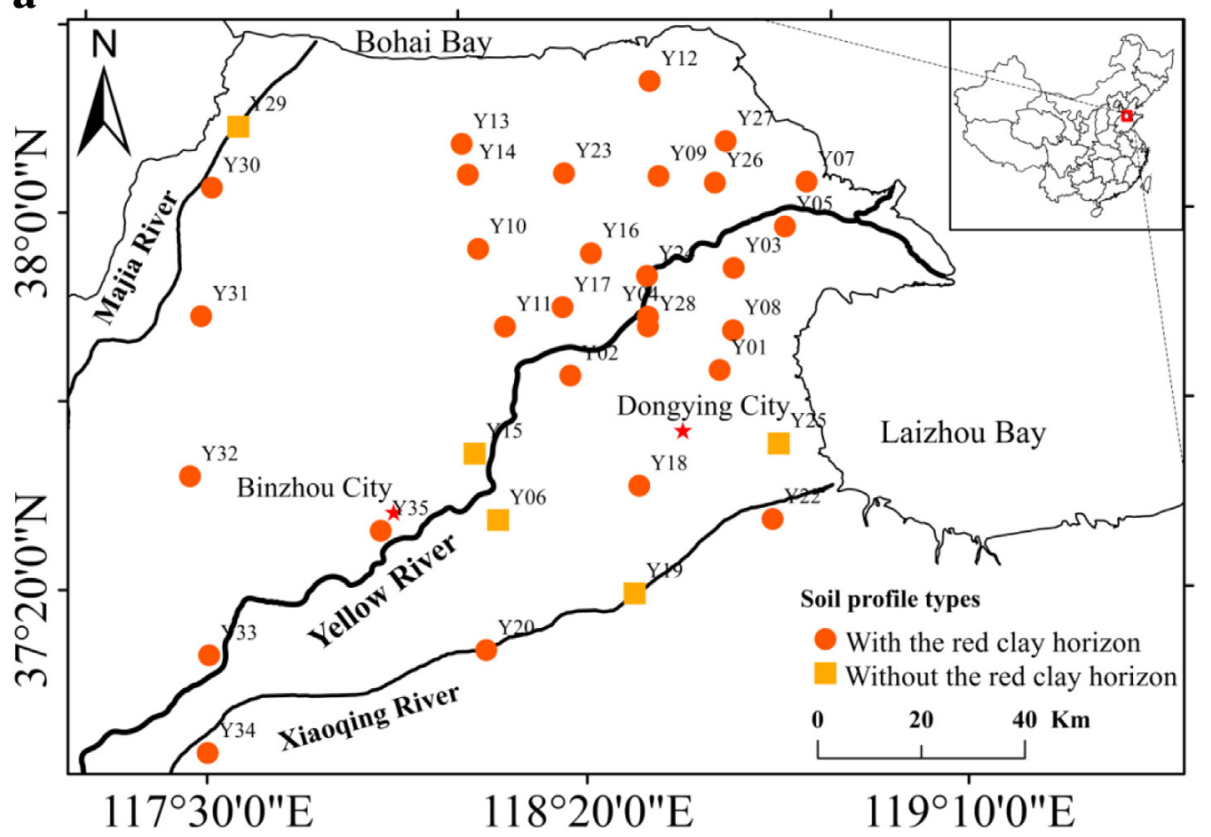

b

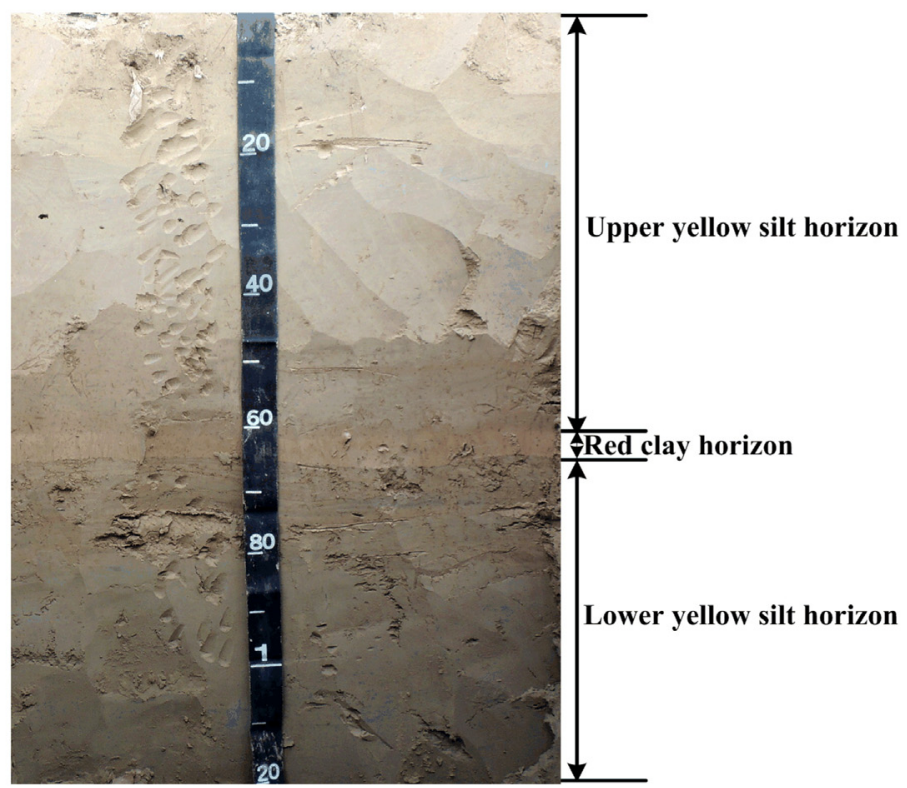

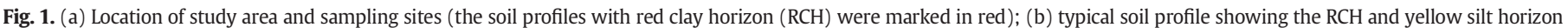
(YSH). (For interpretation of the references to color in this figure legend, the reader is referred to the web version of this article.)

\section{Results and discussion}

\subsection{Physicochemical characteristics of the red clay horizon}

Grain size changes of the soil horizon samples are shown in Fig. 2. The texture classification on the basis of the method described by Shepard (1954) was plotted in a ternary diagram of clay $(<4 \mu \mathrm{m})$, silt

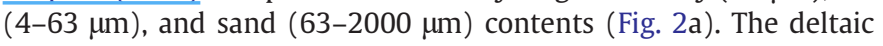
soils revealed three major features including silt, sandy silt and clayey silt. The RCH samples were dominated by clayey silt (67\%) while other soil samples consisted mainly of silt and sandy silt. It was evident that grain size in the $\mathrm{RCH}$ (median grain size $(\mathrm{Md})=11.4 \pm 6.8 \mu \mathrm{m}, \mathrm{n}=$ $42, p<0.01$ ) was significantly finer than its upper ( $\mathrm{Md}=30.1 \pm$ $13.7 \mu \mathrm{m}, \mathrm{n}=52$ ) and lower YSH ( $\mathrm{Md}=35.6 \pm 13.3 \mu \mathrm{m}, \mathrm{n}=26)$. The grain size compositions of the soil samples were generally consistent
Table 1

BCR three-stage sequential extraction scheme.

\begin{tabular}{lll}
\hline $\begin{array}{l}\text { Extraction } \\
\text { step }\end{array}$ & Reagent & Nominal target phase \\
\hline 1 & $\mathrm{CH}_{3} \mathrm{COOH}\left(0.11 \mathrm{~mol} \mathrm{~L}^{-1}\right)$ & $\begin{array}{l}\text { Exchangeable, water and } \\
\text { acid-soluble (e.g. carbonates) } \\
\text { Reducible (e.g. iron/manganese } \\
\text { oxides) }\end{array}$ \\
2 & $\mathrm{NH}_{2} \mathrm{OH} \cdot \mathrm{HCl}\left(0.1 \mathrm{~mol} \mathrm{~L}^{-1}\right)$ & $\begin{array}{l}\text { Oxidizable (e.g. organic matter } \\
\text { and sulfides) } \\
\text { Remaining, non-silicate bound } \\
\text { metals }\end{array}$ \\
\hline
\end{tabular}




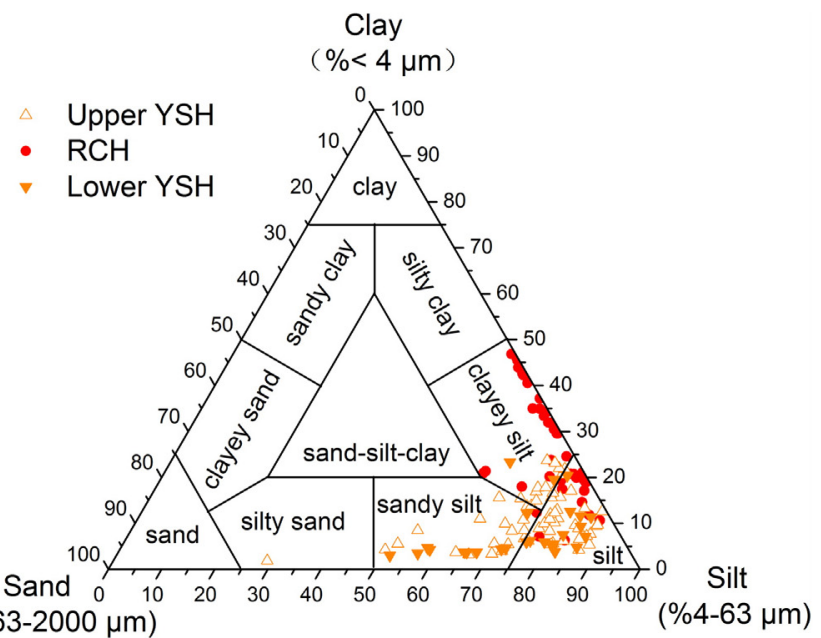

b

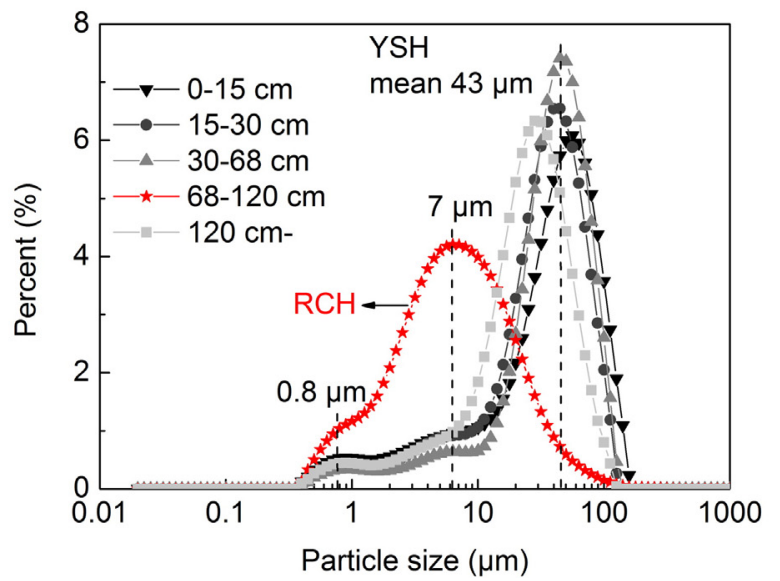

Fig. 2. (a) Ternary diagram of clay/sand/silt proportions of soil samples in the Yellow River Delta; (b) grain-size frequency distributions of typical soil profile with red clay horizon ( $\mathrm{RCH})$.

with the early study of the sediment cores in the YRD, which consisting main units of yellow silt and grayish brown, brown clayey silt described by Xue et al. (1995).

The Y04 soil profile with RCH was used as an example to show the grain size distributions in the soil profiles (Fig. 2b). The frequency curves of the YSH showed bimodal distribution with a poorly sorted fine component and a well sorted coarse component, agreeing with the aeolian loess in northern China (Sun et al., 2004). However, the $\mathrm{RCH}$, which sharing the same fine peak values of the YSH, showed an obviously higher and wider peak in fine component, indicating that the $\mathrm{RCH}$ was formed under a weakly hydrodynamic sorting condition deriving from the deposition of Yellow River sediments. Once the RCH settled, it is difficult to move due to the cohesive properties of the clayey particles. The RCH thus became a potential source or sink of the nutrients and pollutants.
The other physicochemical properties of the three horizon groups are summarized in Table 2. In accordance with the change of grain size, the accumulation of $\mathrm{CEC}$ and $\mathrm{CaCO}_{3}$ could be observed in the $\mathrm{RCH}$, and these two properties had significantly positive correlations with clay content in the studied soil profiles $(p<0.01, \mathrm{n}=120$, data not shown). Generally, the SOM and TN contents are decreasing with depth in soil profiles due to the limited organic matter supply and microbial decomposition in the subsoil horizons. The SOM and TN contents in the RCH approached to that in the upper YSH statistically although most of the RCH samples occurred in the subsoil with a depth of $>35 \mathrm{~cm}$. The enhanced contents of SOM and TN in the RCH could be attributed to the increased contents of minerals and soil aggregates, which were main stabilization phases for organic compounds (Rumpel and Kögel-Knabner, 2011). The trapped organic and inorganic matters together with the high CEC and clay contents make the $\mathrm{RCH}$ to process strong adsorption and ion exchange abilities (Bai et al., 2011). There were no significant difference in salinity and $\mathrm{pH}$ between the $\mathrm{RCH}$ and YSH.

\subsection{Higher intensity of chemical weathering of the red clay horizon}

The formation of red soils in China has been experiencing strong chemical weathering, with the removal of labile cations (mainly $\mathrm{Ca}^{2+}$, $\mathrm{Mg}^{2+}, \mathrm{K}^{+}$and $\mathrm{Na}^{+}$, and Si also partially leached due to the disintegration of silicate minerals) and accumulation of immobile elements $\left(\mathrm{Al}^{3+}\right.$ and $\mathrm{Ti}^{4+}$ ) (Xiong and $\mathrm{Li}, 1987$ ). Therefore, weathering index based on the molecular ratios of mobile and less mobile elements are often used as good measures in revealing chemical weathering intensity. For example, chemical index of alteration (CIA), chemical index of weathering (CIW) and aluminum over silica ( $R$, Ruxton ratio) indices have been well performed in predicting weathering degree of loessred clay deposit in northern and southern China (Xiong et al., 2010; Hu et al., 2010). The increasing values of CIA and CIW, and the decreasing values of $\mathrm{R}$ indicate more weathering. $\mathrm{CIA}$ and $\mathrm{CIW}$ of the $\mathrm{RCH}$ were apparently higher and $\mathrm{R}$ of the $\mathrm{RCH}$ was apparently lower than those of the upper and lower YSH, indicating that the $\mathrm{RCH}$ were more intensively weathered in source area (Table 3). However, the weathering intensity of the RCH was much lower than the Quaternary red earth (QRE) and vermiculated red soil (VRS) in southern China. The QRE had CIA and R values ranging from 69 to 77 and 2.40 to 4.18 (Wang et al., 2013), and the VRS had CIA values ranging from 86 to 89 (Qiao et al., 2011b). The quite different weathering intensity between $\mathrm{RCH}$ in the YRD and red soil in southern China might indicate a different soil formation process. The formation of $\mathrm{RCH}$ was very likely affected by the chemical weathering in source area, as well as by the hydraulic sorting and pedogenesis in deposited area. The CIA values showed that the RCH-YSH sequence in the YRD had been experiencing incipient $(C I A=50-60)$ to intermediate $(\mathrm{CIA}=60-80)$ chemical weathering process, which was similar to the loess-red clay deposit of Chinese Loess Plateau (Xiong et al., 2010).

Usually, lithogenic loess materials have relatively uniform and weak magnetic properties, whereas, ancient soils that are intercalated with loess in loess-paleosol sequences are magnetic enhanced due to neoformation of secondary magnetite/maghemite formation (Liu et al., 2012). The stronger $\chi_{\text {If }}$ signal of the RCH indicated a higher content of ferromagnetic minerals in the $\mathrm{RCH}$ sourcing from iron-bearing clays

Table 2

Variation in soil properties among different soil horizons in soil profiles of the YRD.

\begin{tabular}{|c|c|c|c|c|c|c|}
\hline Soil horizon & $\begin{array}{l}\text { SOM } \\
\mathrm{g} / \mathrm{kg}\end{array}$ & $\begin{array}{l}\mathrm{TN} \\
\mathrm{g} / \mathrm{kg}\end{array}$ & $\begin{array}{l}\mathrm{CEC} \\
\mathrm{cmol} / \mathrm{kg}\end{array}$ & $\begin{array}{l}\mathrm{CaCO}_{3} \\
\%\end{array}$ & $\begin{array}{l}\text { Salinity } \\
\mathrm{g} / \mathrm{kg}\end{array}$ & $\mathrm{pH}$ \\
\hline Upper YSH $(\mathrm{n}=52)$ & $8.76 \pm 6.74 a$ & $0.72 \pm 0.33 a$ & $11.6 \pm 7.9 a$ & $9.09 \pm 1.28 a$ & $3.11 \pm 3.29 a$ & $8.47 \pm 0.30 a$ \\
\hline $\mathrm{RCH}(\mathrm{n}=42)$ & $8.64 \pm 3.76 a$ & $0.77 \pm 0.08 \mathrm{a}$ & $21.1 \pm 6.0 \mathrm{~b}$ & $11.4 \pm 1.1 b$ & $3.78 \pm 2.43 a$ & $8.41 \pm 0.24 a$ \\
\hline Lower YSH $(\mathrm{n}=26)$ & $3.91 \pm 3.78 b$ & $0.51 \pm 0.08 b$ & $9.41 \pm 6.11 a$ & $9.00 \pm 1.06 a$ & $3.53 \pm 2.46 a$ & $8.47 \pm 0.24 a$ \\
\hline
\end{tabular}

Values are mean \pm s.d. Values sharing the same letters in one column are not different at $p>0.05$ (by Duncan test). 
Table 3

Variation in weathering intensity and magnetic properties among different soil horizons in soil profiles of the YRD.

\begin{tabular}{|c|c|c|c|c|c|}
\hline Soil horizon & CIA & CIW & $\mathrm{R}$ & $\begin{array}{l}\chi_{\mathrm{lf}} \\
10^{-8} \mathrm{~m}^{3} / \mathrm{kg}\end{array}$ & $\begin{array}{l}\chi_{\mathrm{fd}} \\
\%\end{array}$ \\
\hline Upper YSH $(n=52)$ & $58.8 \pm 4.7 a$ & $67.1 \pm 5.9 a$ & $8.99 \pm 1.13 a$ & $42.0 \pm 9.9 a$ & $5.11 \pm 1.85 a$ \\
\hline $\mathrm{RCH}(\mathrm{n}=42)$ & $65.3 \pm 5.4 b$ & $75.4 \pm 7.2 b$ & $6.70 \pm 0.98 b$ & $55.6 \pm 12.2 b$ & $8.15 \pm 4.50 b$ \\
\hline Lower YSH $(n=26)$ & $56.3 \pm 4.7 c$ & $64.0 \pm 6.0 c$ & $9.55 \pm 1.02 c$ & $37.1 \pm 17.1 \mathrm{a}$ & $3.90 \pm 1.77 a$ \\
\hline
\end{tabular}

Values are mean \pm s.d. Values sharing the same letters in one column are not different at $p>0.05$ (by Duncan test).

$\mathrm{CIA}=\left[\mathrm{Al}_{2} \mathrm{O}_{3} /\left(\mathrm{Al}_{2} \mathrm{O}_{3}+\mathrm{CaO}^{*}+\mathrm{Na}_{2} \mathrm{O}+\mathrm{K}_{2} \mathrm{O}\right)\right] \times 100$.

$\mathrm{CIW}=\left[\mathrm{Al}_{2} \mathrm{O}_{3} /\left(\mathrm{Al}_{2} \mathrm{O}_{3}+\mathrm{CaO}^{*}+\mathrm{Na}_{2} \mathrm{O}\right)\right] \times 100$.

$\mathrm{R}=\mathrm{SiO}_{2} / \mathrm{Al}_{2} \mathrm{O}_{3}$.

$\mathrm{CaO}^{*}$ is the amount of $\mathrm{CaO}$ in the silicate minerals in molecular proportions.

and mafic silicates (Spassov et al., 2003). This was also consistent with its higher degree of source-area weathering and pedogenesis compared to the YSH (Table 3 ). $\chi_{\mathrm{fd}} \%$ is sensitive to the relative concentration of ultrafine superparamagnetic (SP) particles ( $<30 \mathrm{~nm}$ diameter) in soils, with $\chi_{\mathrm{fd}} \%>6 \%$ indicating the presence of SP particles (Dearing et al., 1996). $\chi_{\mathrm{fd}} \%$ of the RCH and YSH respectively ranged from 4.1 to $11.0 \%$ and 0 to $9.8 \%$, implying the higher content of SP particles in the $\mathrm{RCH}$. $\chi_{\mathrm{fd}} \%$ was also significantly positively correlated with $\chi_{\mathrm{If}}\left(p<0.01, \mathrm{R}^{2}=\right.$ 0.581 ), suggesting that the magnetic properties were mainly controlled by secondary ferrimagnetic minerals (SP or stable single domain particles) in the RCH-YSH sequence in the YRD. The result was similar with previous studies in loess-red clay sequence in Chinese Loess Plateau (Hu et al., 2009; Qiang et al., 2005).

\subsection{Heavy metal accumulation associated with the distinctive soil properties in the red clay horizons}

The mean and range of $\mathrm{Cu}, \mathrm{Zn}, \mathrm{Cr}, \mathrm{Ni}, \mathrm{Pb}, \mathrm{Co}$ and $\mathrm{Cd}$ concentrations at different soil horizons are summarized in Table 4 . The heavy metals except for $\mathrm{Cd}$ were significantly accumulated in the $\mathrm{RCH}$, which had the mean heavy metal concentrations of about 1.5 times as high as the YSH. Although mean value of $\mathrm{Cd}$ in the $\mathrm{RCH}$ was comparable with that in the YSH, the maximum concentration of $\mathrm{Cd}$ in the $\mathrm{RCH}$ was also about 1.5 times of those in the YSH. The heavy metal concentrations were not significantly different between the upper and lower YSH except for $\mathrm{Zn}$ and $\mathrm{Pb}$, indicating few contaminant inputs from anthropogenic activities. This could also be confirmed by the $I_{\text {geo }}$ values as shown in Table 4. For all heavy metals except for $\mathrm{Cd}$, the $I_{\text {geo }}$ values occurred at unpolluted levels $\left(I_{\text {geo }}<0\right)$. The moderately polluted level $\left(1<I_{\text {geo }}<2\right)$ of Cd was resulting from its high concentration in the Yellow River sediment, which was a major source of heavy metals in the YRD (Li et al., 2014). Although no significant heavy metal pollution exists in soil, the mean $I_{\text {geo }}$ values of the $\mathrm{Cu}, \mathrm{Zn}, \mathrm{Cr}, \mathrm{Ni}, \mathrm{Pb}$ and $\mathrm{Co}$ in $\mathrm{RCH}$ were significantly higher than that in the YSH $(p<0.05)$. The accumulation of heavy metals in the subsoil rather than topsoil exhibited the risk of leaching of mobilized metals downward the soil profile and consequently posed a threat to local groundwater. The $I_{\mathrm{PO}}$ shown in Table 4 was calculated based on the BCR results shown in Fig. 4. Higher $I_{\text {POL }}$ values were found for $\mathrm{Pb}, \mathrm{Co}$ and $\mathrm{Cd}$ in the $\mathrm{RCH}$ than in the YSH. This could be attributed to the higher content of $\mathrm{Fe}-\mathrm{Mn}$ oxides in the $\mathrm{RCH}$, which could retain substantial amounts of metals in the $\mathrm{RCH}$. The results of the total contents, $I_{\text {geo }}$ and $I_{\mathrm{POLL}}$ all indicated the significant accumulation of heavy metals in the $\mathrm{RCH}$

The PCA was performed with the values of the heavy metals $(\mathrm{Cu}, \mathrm{Zn}$, $\mathrm{Cr}, \mathrm{Ni}, \mathrm{Pb}, \mathrm{Co}$ and $\mathrm{Cd}$ ) and selected soil properties ( $\mathrm{Al}, \mathrm{Fe}, \mathrm{CaCO}_{3} \mathrm{SOM}$, clay, CIA, $\chi_{\mathrm{If}}$ and $\left.\chi_{\mathrm{fd}}\right)$ for the RCH and YSH to assist in the identification of metal sources (Fig. 3). Two factors describe more than $80 \%$ of the total variance. For the YSH (Fig. 3a), most heavy metals $(\mathrm{Cu}, \mathrm{Zn}, \mathrm{Cr}, \mathrm{Ni}$, $\mathrm{Co}$ and $\mathrm{Cd}$ ) were significantly correlated with the $\mathrm{Al}, \mathrm{Fe}$, and CIA. Only $\mathrm{Pb}$ was associated with clay content. Being different from the YSH, the group of $\mathrm{Cu}, \mathrm{Zn}, \mathrm{Cr}, \mathrm{Ni}, \mathrm{Co}$ and $\mathrm{Pb}$ in the $\mathrm{RCH}$ was significantly correlated with clay content and other lithogenic properties (Fig. 3b). This implied that the distribution of heavy metals in the $\mathrm{RCH}$ with higher weathering intensity was more influenced by the clay minerals than that in the YSH. However $\mathrm{Co}$, was poorly correlated with other elements in the PCA analysis, which might have different sources. The PCA results strongly suggested the sorption of heavy metals by aluminosilicates and oxides. The weathering of parent materials could produce secondary minerals, especially clay minerals and iron oxides, which have high surface activity to stabilize heavy metals. Considering the low concentrations of heavy metals in the YRD, the strong correlation between heavy metals and lithogenic parameters in both YSH and $\mathrm{RCH}$ indicated that the source weathering and pedogenesis processes were key factors to influence the variability of the metal content in the soil profiles.

\subsection{Heavy metal fractions in the typical red clay horizon}

Two soil profiles with 5 samples in the upper YSH, 3 samples in the $\mathrm{RCH}$ and 2 samples in the lower YSH were used to determine the chemical fractionation of heavy metals. According to the BCR method, heavy metal fractions were categorized as exchangeable, reducible, oxidizable, and residual with decreasing mobility. The percentages of these fractions are shown in Fig. 4. The heavy metals were generally dominant in residual fraction. Few metals except for $\mathrm{Cd}$ were associated with exchangeable fraction. These results were consistent with the findings for sediments in the Yellow River estuary reported by Liu et al. (2015). The low proportion of metals in the mobile fractions (exchangeable + reducible + oxidizable) and high levels of immobile fraction (residual) indicated that the soil was relatively unpolluted (Davidson et al., 1994), which further confirmed the predominantly lithogenic inputs of heavy metals in the YRD.

In spite of the high proportion found for the residual fraction, it can be seen that the heavy metals were second dominant in the reducible fraction for $\mathrm{Cu}, \mathrm{Zn}, \mathrm{Ni}, \mathrm{Pb}$ and $\mathrm{Co}$, especially for $\mathrm{Pb}$ (23.753.6\%) and Co (10.5-31.5\%). Previous studies had shown that $\mathrm{Fe}-\mathrm{Mn}$ hydrous oxides were important binding sites of $\mathrm{Pb}$ in soils and played an important role in controlling its mobility in the environment (Rodríguez et al., 2009; Singh et al., 2005). Cobalt has also been found to be associated with Fe-Mn oxides by several authors (Dundar et al., 2012; Krasnodębska-Ostręga et al., 2001). In different soil horizons, the $\mathrm{RC}$ had higher levels of $\mathrm{Pb}(48.2 \pm 5.5 \%)$ and $\mathrm{Co}$ $(29.8 \pm 1.6 \%)$ associated with reducible fraction than that in the YSH ( $32.6 \pm 4.4$ and $17.2 \pm 3.9 \%$, respectively), which could be attributed to the higher content of iron oxide in the $\mathrm{RCH}$ as revealed by $\chi_{\text {If }}$ values. It should be pointed out that the RCH occurred in subsoil might experience reduced conditions, which could release $\mathrm{Pb}$ and Co by decomposition of the oxides and consequently affecting soil quality and biota. The mobility (exchangeable + reducible + oxidizable) of $\mathrm{Cu}, \mathrm{Zn}, \mathrm{Cr}$ and $\mathrm{Ni}$ in the $\mathrm{RCH}$ (mean 16.0, 11.8, 8.0 and $28.9 \%$, respectively) was comparable with that in the YSH (mean $16.4,14.1,6.6$ and $26.5 \%$, respectively).

In the investigated heavy metals, only $\mathrm{Cd}$ was found with relatively high proportion in the exchangeable fraction (11.1-23.5\%), indicating a high availability of lithogenic $\mathrm{Cd}$ in the soils. In different soil horizons, the proportion of exchangeable and reducible $\mathrm{Cd}$ in the $\mathrm{RCH}(22.7 \pm$ $0.8 \%$ and $12.4 \pm 1.4 \%$, respectively) was much higher than that in the 
Y. Li et al. / Journal of Geochemical Exploration xxx (2015) xxx-xxx
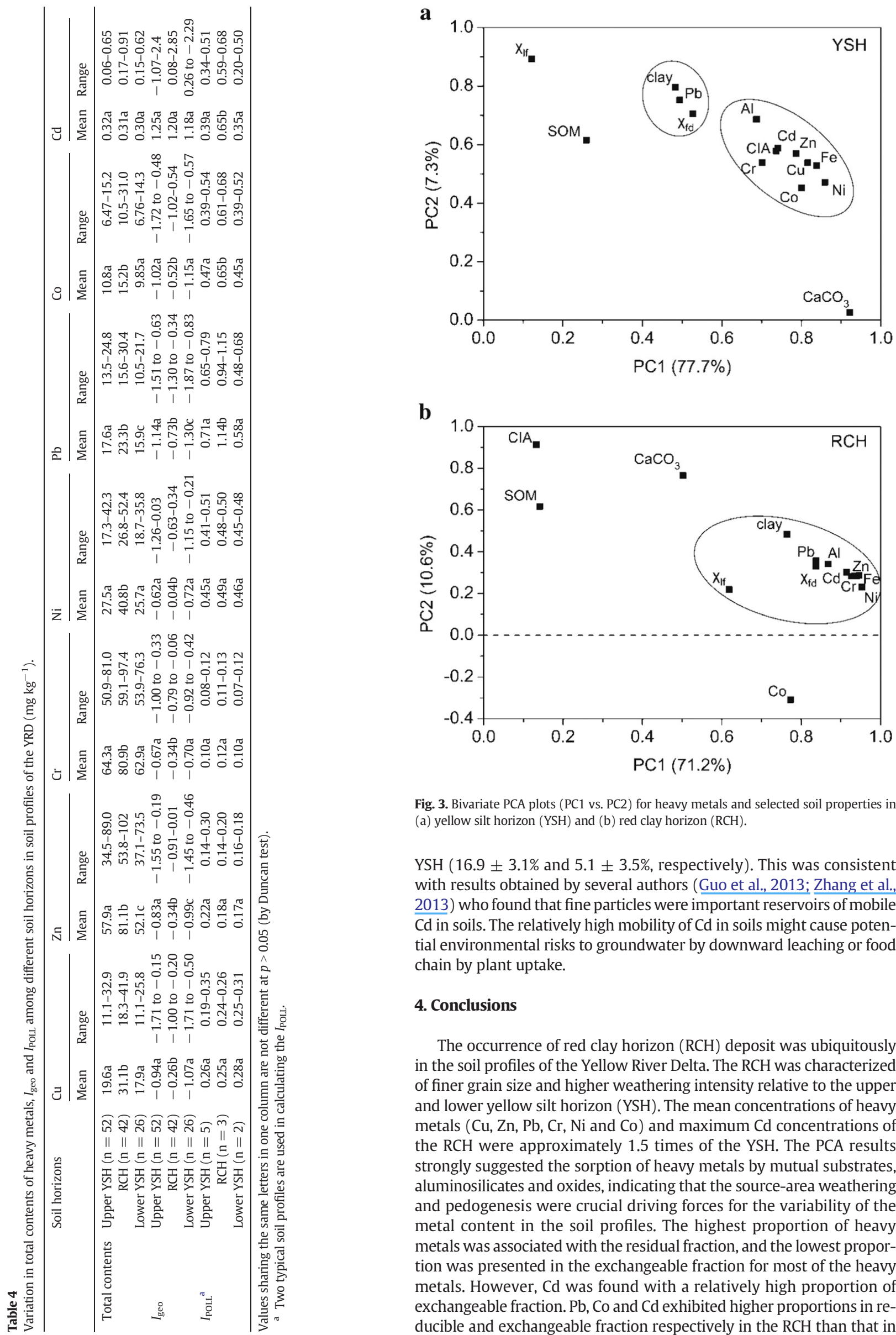

Fig. 3. Bivariate PCA plots (PC1 vs. PC2) for heavy metals and selected soil properties in (a) yellow silt horizon (YSH) and (b) red clay horizon (RCH).

YSH ( $16.9 \pm 3.1 \%$ and $5.1 \pm 3.5 \%$, respectively). This was consistent with results obtained by several authors (Guo et al., 2013; Zhang et al., 2013) who found that fine particles were important reservoirs of mobile $\mathrm{Cd}$ in soils. The relatively high mobility of $\mathrm{Cd}$ in soils might cause potential environmental risks to groundwater by downward leaching or food chain by plant uptake.

\section{Conclusions}

The occurrence of red clay horizon ( $\mathrm{RCH}$ ) deposit was ubiquitously in the soil profiles of the Yellow River Delta. The RCH was characterized of finer grain size and higher weathering intensity relative to the upper and lower yellow silt horizon (YSH). The mean concentrations of heavy metals $(\mathrm{Cu}, \mathrm{Zn}, \mathrm{Pb}, \mathrm{Cr}, \mathrm{Ni}$ and $\mathrm{Co})$ and maximum $\mathrm{Cd}$ concentrations of the RCH were approximately 1.5 times of the YSH. The PCA results strongly suggested the sorption of heavy metals by mutual substrates, aluminosilicates and oxides, indicating that the source-area weathering and pedogenesis were crucial driving forces for the variability of the metal content in the soil profiles. The highest proportion of heavy metals was associated with the residual fraction, and the lowest proportion was presented in the exchangeable fraction for most of the heavy metals. However, Cd was found with a relatively high proportion of exchangeable fraction. $\mathrm{Pb}, \mathrm{Co}$ and $\mathrm{Cd}$ exhibited higher proportions in reducible and exchangeable fraction respectively in the $\mathrm{RCH}$ than that in 
$\%$ of total content

$\mathrm{Cu}$

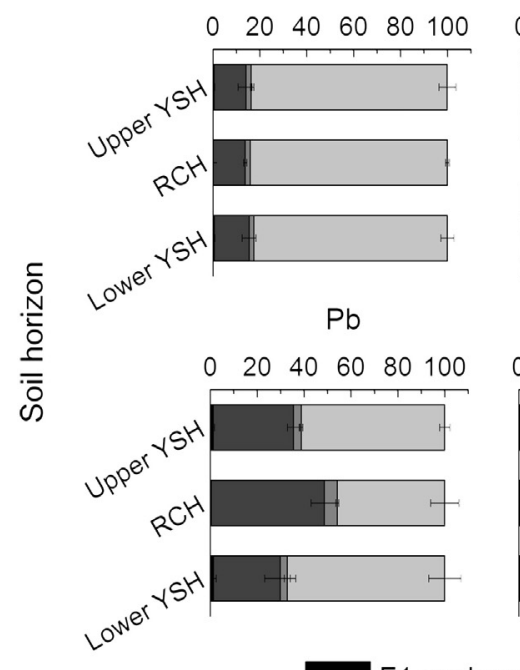

$\mathrm{Zn}$

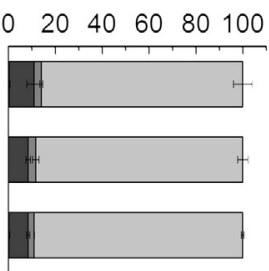

Co

$2040 \quad 60 \quad 80100$

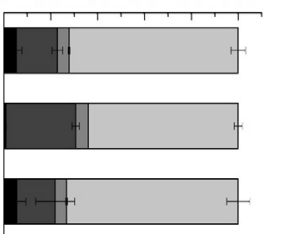

$\mathrm{Cr}$
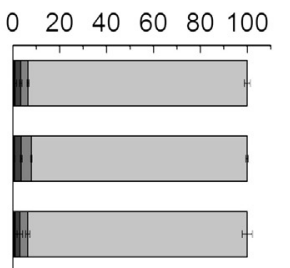

$\mathrm{Cd}$

$0 \quad 20406080100120$

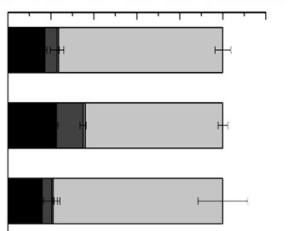

$\square$ F1 exchangeable $\square$ F2 Reducible $\square$ F3 Oxidizable

Residual

Fig. 4. Percentage of heavy metal fractionation in different soil horizons using BCR method.

the YSH, implying a higher potential environmental risk for the metals in the $\mathrm{RCH}$. The fractions of other metals $(\mathrm{Cu}, \mathrm{Zn}, \mathrm{Cr}$ and $\mathrm{Ni})$ in the $\mathrm{RCH}$ were consistent with that in the YSH.

\section{Acknowledgments}

The authors are grateful for the financial support from the Science and Technology Development Program of Yantai (2013ZH080), National Natural Science Foundation of China (NSFC) $(41230858,41171248)$ and the Key Research Program of the Chinese Academy of Sciences (KZZD-EW-14).

\section{References}

Bai, J.H., Xiao, R., Cui, B.S., Zhang, K.J., Wang, Q.G., Liu, X.H., Gao, H.F., Huang, L.B., 2011. Assessment of heavy metal pollution in wetland soils from the young and old reclaimed regions in the Pearl River Estuary, South China. Environ. Pollut. 159, 817-824.

Bai, J.H., Xiao, R., Zhang, K.J., Gao, H.F., 2012. Arsenic and heavy metal pollution in wetland soils from tidal freshwater and salt marshes before and after the flow-sediment regulation regime in the Yellow River Delta, China. J. Hydrol. 450-451, 244-253.

Burkhardt, E.M., Bischoff, S., Akob, D.M., Büchel, G., Küsel, K., 2011. Heavy metal tolerance of Fe (III)-reducing microbial communities in contaminated creek bank soils. Appl. Environ. Microbiol. 77, 3132-3136.

Cheng, H.X., Li, M., Zhao, C.D., Li, K., Peng, M., Qin, A.H., Cheng, X.M., 2014. Overview of trace metals in the urban soil of 31 metropolises in China. J. Geochem. Explor. 139, $31-52$.

China National Environmental Monitoring Center (CNEMC), 1990. Chinese Elemental Background Values for Soils. Chinese Environmental Science, Beijing (in Chinese).

Davidson, C.M., Thomas, R.P., McVey, S.E., 1994. Evaluation of a sequential extraction procedure for the speciation of heavy metals in sediments. Anal. Chim. Acta 291 $277-286$.

Dearing, J.A., Dann, R.J.L., Hay, K., Lees, J.A., Loveland, P.J., Maher, B.A., O'Grady, K., 1996. Frequency-dependent susceptibility measurements of environmental materials, Geophys. J. Int. 124, 228-240.

Dundar, M.S., Altundag, H., Eyupoglu, V., Keskin, S.C., Tutunoglu, C., 2012. Determination of heavy metals in lower Sakarya river sediments using a BCR-sequential extraction procedure. Environ. Monit. Assess. 184, 33-41.

Guo, G.L., Zhang, Y., Zhang, C., Wang, S.J., Yan, Z.G., Li, F.S., 2013. Partition and characterization of cadmium on different particle-size aggregates in Chinese Phaeozem. Geoderma 200-201, 108-113.

Hu, X.F., Xu, L.F., Pan, Y., Shen, M.N., 2009. Influence of the aging of Fe oxides on the decline of magnetic susceptibility of the Tertiary red clay in the Chinese Loess Plateau. Quat. Int. 209, 22-30.

Hu, X.F., Wei, J., Du, Y., Xu, L.F., Wang. H.B., Zhang, G.L., Ye, W., Zhu, L.D., 2010. Regional distribution of the Quaternary Red Clay with aeolian dust characteristics in subtropical China and its paleoclimatic implications. Geoderma 159, 317-334.

Kabala, C., Singh, B.R., 2001. Fractionation and mobility of copper, lead, and zinc in soil profiles in the vicinity of a copper smelter. J. Environ. Qual. 30, 485-492.
Karbassi, A.R., Monavari, S.M., Bidhendi, G.R.N., Nouri, J., Nematpour, K., 2008. Metal pollution assessment of sediment and water in the Shur River. Environ. Monit. Assess. $147,107-116$.

Krasnodębska-Ostręga, B., Emons, H., Golimowski, J., 2001. Selective leaching of elements associated with Mn-Fe oxides in forest soil, and comparison of two sequential extraction methods. Fresenius J. Anal. Chem. 371, 385-390.

Lamy, I., Van Oort, F., Dère, C., Baize, D., 2006. Use of major-and trace-element correlations to assess metal migration in sandy Luvisols irrigated with wastewater. Eur. J. Soil Sci. 57, 731-740.

Li, Y., Zhang, H.B., Chen, X.B., Tu, C., Luo, Y.M., Christie, P., 2014. Distribution of heavy metals in soils of the Yellow River Delta: concentrations in different soil horizons and source identification. J. Soils Sediments 14, 1158-1168

Liu, Q.S., Roberts, A.P., Larrasoaña, J.C., Banerjee, S.K., Guyodo, Y., Tauxe, L., Oldfield, F., 2012. Environmental magnetism: principles and applications. Rev. Geophys. 50, RG4002.

Liu, H.Q., Liu, G.J., Da, C.N., Yuan, Z.J., Wang, J., 2015. Concentration and fractionation of heavy metals in the Old Yellow River Estuary, China. J. Environ. Qual. 44, $174-182$.

Luo, Y.M., Christie, P., 1998a. Choice of extraction technique for soil reducible trace metals determines the subsequent oxidisable metal fraction in sequential extraction schemes. Int. J. Environ. An. Ch. 72, 59-75.

Luo, Y.M., Christie, P., 1998b. Bioavailability of copper and zinc in soils treated with alkaline stabilized sewage sludges. J. Environ. Qual. 27, 335-342.

Milliman, J.D., Syvitski, J.P.M., 1992. Geomorphic/tectonic control of sediment discharge to the ocean: the importance of small mountainous rivers. J. Geol. 100, 525-544.

Müller, G., 1979. Schwermetalle in den sediments des Rheins-Veranderungen Seitt. Umschan 79, 778-783.

Nemati, N., Bakar, N.K.A., Abas, M.R., Sobhanzadeh, E., 2011. Speciation of heavy metals by modified BCR sequential extraction procedure in different depths of sediments from Sungai Buloh, Selangor, Malaysia. J. Hazard. Mater. 192, 402-410.

Pang, J.Z., Si, S.H., 1980. Fluvial process of the Huanghe River Estuary II-hydrographical character and the region of sediment silting. Oceanol. Limnol. Sin. 11, 295-305 (in Chinese with English abstract).

Pretorius, W., Weis, D., Williams, G., Hanano, D., Kieffer, B., Scoates, J., 2006. Complete trace elemental characterisation of granitoid (USGS G-2, GSP-2) reference materials by high resolution inductively coupled plasma-mass spectrometry. Geostand. Geoanal. Res. 30, 39-54.

Qiang, X.K., An, Z.S., Li, H.M., Chang, H., Song, Y.G., 2005. Magnetic properties of Jiaxian red clay sequences from northern Chinese Loess Plateau and its paleoclimatic significance. Sci. China Earth Sci. 48, 1234-1245.

Qiao, S.Q., Shi, X.F., Saito, Y., Li, X.Y., Yu, Y.G., Bai, Y.Z., Liu, Y.G., Wang, K.S., Yang, G., 2011a. Sedimentary records of natural and artificial Huanghe (Yellow River) channel shifts during the Holocene in the southern Bohai Sea. Cont. Shelf Res. 31, 1336-1342.

Qiao, Y.S., Hao, Q.Z., Peng, S.S., Wang, Y., Li, J.W., Liu, Z.X., 2011b. Geochemical characteristics of the eolian deposits in southern China, and their implications for provenance and weathering intensity. Palaeogeogr. Palaeoclimatol. Palaeoecol. 308, 513-523.

Rodríguez, L., Ruiz, E., Alonso-Azcárate, J., Rincón, J., 2009. Heavy metal distribution and chemical speciation in tailings and soils around a $\mathrm{Pb}-\mathrm{Zn}$ mine in Spain. J. Environ. Manag. 90, 1106-1116.

Rumpel, C., Kögel-Knabner, I., 2011. Deep soil organic matter-a key but poorly understood component of terrestrial C cycle. Plant Soil 338, 143-158.

Selim, H.M., 2013. Transport and retention of heavy metal in soils: competitive sorption. Adv. Agron. 119, 275-308. 
Shepard, F.P., 1954. Nomenclature based on sand-silt-clay ratios. J. Sediment. Petrol. 24, 151-158.

Singh, K.P., Mohan, D., Singh, V.K., Malik, A., 2005. Studies on distribution and fractionation of heavy metals in Gomti river sediments-a tributary of the Ganges, India. J. Hydrol. 312, 14-27.

Spassov, S., Heller, F., Kretzschmar, R., Evans, M.E., Yue, L.P., Nourgaliev, D.K., 2003. Detrital and pedogenic magnetic mineral phases in the loess/palaeosol sequence at Lingtai (Central Chinese Loess Plateau). Phys. Earth Planet. Inter. 140, 255-275.

Sterckeman, T., Douay, F., Proix, N., Fourrier, H., 2000. Vertical distribution of Cd, Pb and $\mathrm{Zn}$ in soils near smelters in the North of France. Environ. Pollut. 107, 377-389.

Sun, D.H., Bloemendal, I., Rea, D.K., An, Z.S., Vandenderghe, I., Lu, H.Y., Su, R.X., Liu, T.S. 2004. Bimodal grain-size distribution of Chinese loess, and its palaeoclimatic implications. Catena 55, 325-340.

Tessier, A., Campbell, P.G.C., Bisson, M., 1979. Sequential extraction procedure for the speciation of particulate trace metals. Anal. Chem. 51, 844-850.

Vacca, A., Bianco, M.R., Murolo, M., Violante, P., 2012. Heavy metals in contaminated soils of the Rio Sitzerri floodplain (Sardinia, Italy): characterization and impact on pedodiversity. Land Degrad. Dev. 23, 350-364.

Wang, S.Y., Lin, S., Lu, S.G., 2013. Rock magnetism, iron oxide mineralogy and geochemistry of Quaternary red earth in central China and their paleopedogenic implication. Palaeogeogr. Palaeoclimatol. Palaeoecol. 379-380, 95-103.

Xie, Z.L., Zhao, G.S., Sun, Z.G., Liu, J.Y., 2014. Comparison of arsenic and heavy metals contamination between existing wetlands and wetlands created by river diversion in the Yellow River estuary, China. Environ. Earth Sci. 72, 1667-1681.
Xiong, Y., Li, Q.K., 1987. Soils in China. second edition. Science Press, Beijing, pp. 495-537 (in Chinese).

Xiong, S.F., Ding, Z.L., Zhu, Y.J., Zhou, R., Lu, H.J., 2010. A 6 Ma chemical weathering history, the grain size dependence of chemical weathering intensity, and its implications for provenance change of the Chinese loess-red clay deposit. Quat. Sci. Rev. 29, 1911-1922.

Xue, C.T., Zhu, X.H., Lin, H.M., 1995. Holocene sedimentary sequence, foraminifera and ostracoda in west coastal lowland of Bohai Sea, China. Quat. Sci. Rev. 14, 521-530.

Xue, C.T., Ye, S.Y., Gao, M.S., Ding, X.G., 2009. Determination of depositional age in the Huanghe Delta in China. Acta Oceanol. Sin. 31, 117-124 (in Chinese with English abstract).

Yao, X.Y., Xiao, R., Ma, Z.W., Xie, Y., Zhang, M.X., Yu, F.H., 2015. Distribution and contamination assessment of heavy metals in soils from tidal flat, oil exploitation zone and restored wetland in the Yellow River Estuary. Wetlands. http://dx.doi.org/10.1007 s13157-015-0637-3.

Yi, S., Saito, Y., Oshima, H., Zhou, Y.Q., Wei, H.L., 2003. Holocene environmental history inferred from pollen assemblages in the Huanghe (Yellow River) delta, China: climatic change and human impact. Quat. Sci. Rev. 22, 609-628.

Zhang, H.B., Luo, Y.M., Makino, T., Wu, L.H., Nanzyo, M., 2013. The heavy metal partition in size-fractions of the fine particles in agricultural soils contaminated by waste water and smelter dust. J. Hazard. Mater. 248-249, 303-312. 